\title{
OCUPAÇÃO URBANA, USO DA TERRA E CONFLITOS SOCIOAMBIENTAIS NA BACIA DO IGARAPÉ MATA FOME EM BELÉM, PARÁ
}

\author{
Marcos Jonatas Damasceno da Silva ${ }^{(a)}$, Carlos Alexandre Leão Bordalo ${ }^{(b)}$ \\ (a) Professor de Ensino Fundamental da Rede Pública de Acará, Pará: jonatas.marcos@hotmail.com \\ (b) Professor da Faculdade de Geografia e Cartografia, Universidade Federal do Pará: carlosbordalo@ oi.com.br \\ EIXO: BACIAS HIDROGRÁFICAS E RECURSOS HÍDRICOS: ANÁLISE PLANEJAMENTO E \\ GESTÃO
}

\begin{abstract}
Resumo
A Bacia Hidrográfica do Igarapé Mata Fome em Belém, Pará, a partir dos anos 1980, vem passando por modificações socioespaciais devido o processo de ocupação urbana, que levou a diferentes usos da terra. Assim, este trabalho tem como objetivo analisar os conflitos socioambientais na Bacia do Mata Fome decorrentes dos usos da terra provocados pela ocupação urbana. Nesse sentido, foi realizado um breve histórico do processo de ocupação da área de estudo e um mapeamento do uso da terra utilizando como base cartográfica a imagem do satélite Ikonos, ano 2006, com resolução de 1:10000. Os resultados demonstram que a ocupação urbana na referida bacia, ocasionou, entre outros problemas, conflitos pelo uso da terra entre os moradores das ocupações espontâneas e proprietários fundiários e pela água entre os primeiros e a Prefeitura de Belém.
\end{abstract}

Palavras-chave: Bacia hidrográfica; Ocupação urbana; Conflitos; Mata Fome; Belém.

\section{Introdução}

A Bacia Hidrográfica do Igarapé Mata Fome em Belém, Pará, vem passando por muitas transformações socioespaciais em função do processo de ocupação urbana. Este processo teve inicio em meados dos anos 1980 devido à expansão da malha urbana do município de Belém, ocasionada pelo projeto da prefeitura de desconcentrar a população da área central da cidade (FERNANDES 1997; TRINDADE JUNIOR, 1998). Nesse contexto, os conjuntos habitacionais construídos pelo poder público, por meio da Companhia de Habitação (COHAB) e do Instituto de Assistência dos Servidores do Estado do Pará (IPASEP) foram os precursores na ocupação urbana do Mata Fome (TRINDADE JUNIOR, 1998).

De acordo com Rodrigues (1996) e Trindade Junior (1998), ainda na década de 1980 e aproveitandose da infraestrutura desses conjuntos, surge em seus arredores as ocupações espontâneas, que são precárias moradias construídas em terrenos privados ou públicos, por uma parcela da população que não tem condições de comprar ou alugar uma casa. É através dessas ocupações que os agentes sociais excluídos tornam-se efetivamente agentes modeladores, produzindo seu próprio espaço (CORRÊA, 
1995). Já na década de 1990, outro agente modelador do espaço urbano, passa a atuar na Bacia do Mata Fome: os promotores imobiliários privados. Estes, com o objetivo de atender a uma parcela da população de maior poder aquisitivo, vem construindo alguns condomínios fechados na Bacia do Mata Fome.

A ocupação, urbana por promover uma diversificação dos usos da terra, onde as ocupações espontâneas ocupam papel de destaque, sendo responsável por $49,9 \%$ das edificações acarretou conflitos socioambientais, que têm como atores sociais envolvidos os moradores das ocupações espontâneas, os proprietários das terras ocupadas e a Prefeitura Municipal de Belém. Como mostra Little (2001), esses conflitos podem ocorrer pelo controle dos recursos naturais, como a terra, por exemplo, como território de moradia e vivência. Os conflitos ocorrem também quando há manifestações, por parte da população, no sentido da oferta de serviços públicos.

No Mata Fome, os conflitos se dão em duas frentes: entre os moradores das ocupações espontâneas e os proprietários fundiários e entre os primeiros e a Prefeitura de Belém. No primeiro caso, o conflito se dá pelo uso da terra. Já no segundo, pelo uso da água. Assim, este trabalho tem como objetivo analisar os conflitos socioambientais na Bacia do Igarapé Mata Fome decorrente dos diferentes usos da terra provocada pela ocupação urbana na área de estudo.

A Bacia do Igarapé Mata Fome localiza-se no Distrito Administrativo do Bengui (DABEN) em Belém, possuindo área de $8,3 \mathrm{Km}^{2}$. Sua nascente esta localizada próximo à Rodovia Augusto Montenegro e sua foz deságua na Baía de Guajará, limitando-se ao Norte com a Bacia hidrográfica do Cajé, a Leste com a Bacia hidrográfica do IgarapéMaguari, a Oeste com a Baía de Guajará e ao Sul com a Bacia hidrográfica do Val-de-Cans. Nela estão inseridos os bairros São Clemente, Tapanã, Tapanã e Pratinha (Figura 1).

\section{Metodologia}

Para a elaboração deste trabalho foi realizado um levantamento bibliográfico, onde foram utilizados principalmente os trabalhos de Ferreira (1995), Fernandes (1997) e Trindade Junior (1998) que abordam o processo de expansão urbana de Belém e das ocupações de áreas de várzeas nesta cidade. No que refere aos estudos dos conflitos socioambientais foram utilizados os trabalhos de Little (2001) e Acselrad (2004). A análise dos conflitos foi baseada na metodologia proposta por Thual (1986) e adaptada por Vianna (2002), que analisa os conflitos levando em consideração três elementos como pares dialéticos, a saber, o espaço, que é o local onde as relações de conflito entre os atores sociais envolvidos se desenvolvem; as intenções, que são intenções e ações que cada um dos grupos envolvidos tem sobre os recursos que tem sendo objeto de conflitos e por último, o tempo, que se refere à faixa temporal em que as relações de conflito ocorrem. Foram realizadas visitas a área de estudo para fins de reconhecimento, conversas com moradores e presidentes de associações 
comunitárias, além de mapeamento de uso da terra utilizando-se como base cartográfica a imagem do satélite Ikonos, do ano de 2006.

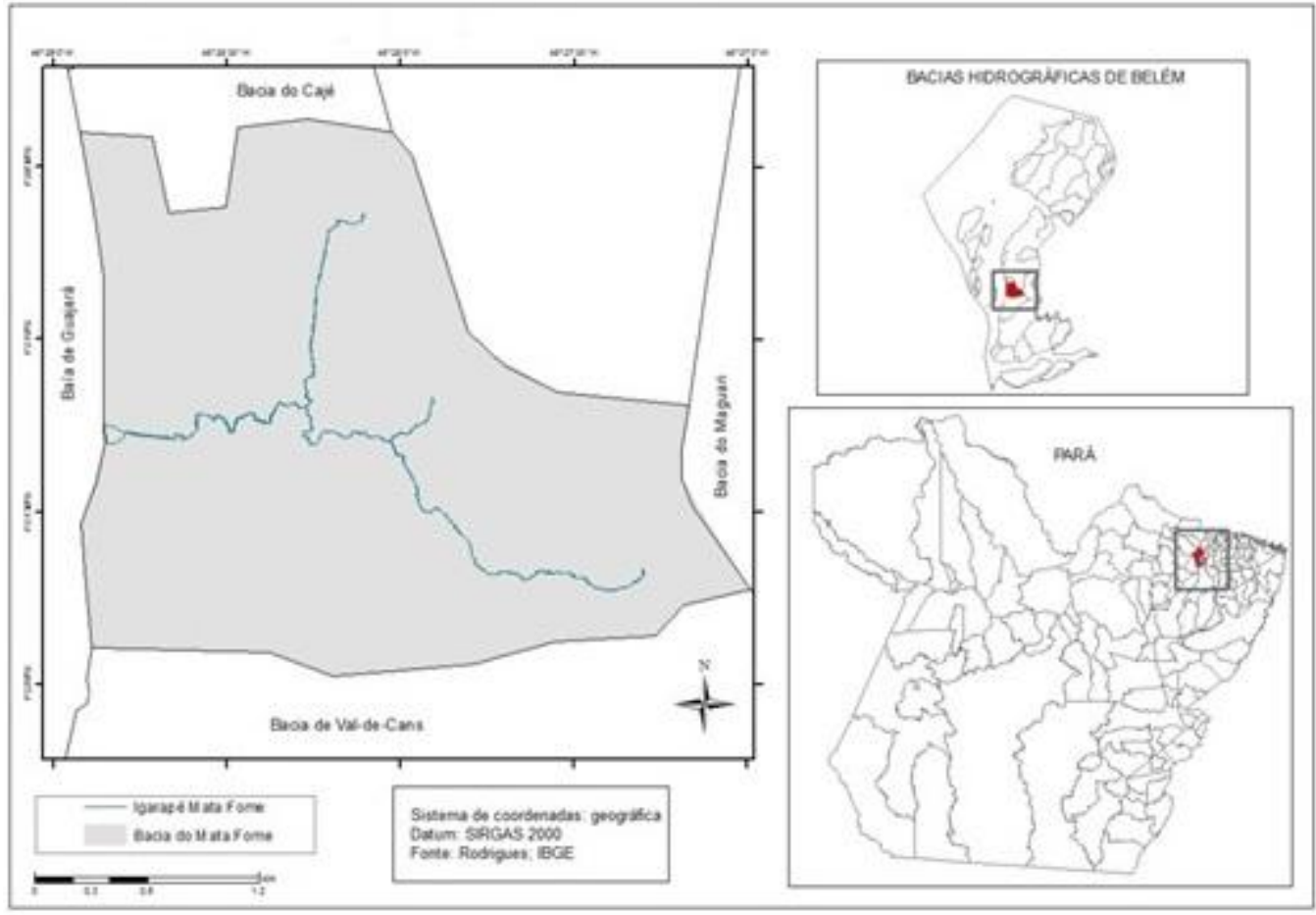

Figura 1 - Mapa de localização da área de estudo. Elaborado por SILVA, 2017.

\section{Ocupação urbana na Bacia do Igarapé Mata Fome.}

A ocupação urbana da Bacia do Igarapé Mata Fome, remonta à metade da década de 1980 e é resultado da expansão da malha urbana de Belém. De acordo com Trindade Junior (1998), a capital paraense, a partir da década de 1970, passou por um processo de expansão, devido à estratégia do governo de desconcentrar a população da área central da cidade. Assim, muitos desses moradores foram assentados em áreas periféricas da cidade e a Rodovia Augusto Montenegro, segundo Fernandes (1997), tornou-se o principal vetor de crescimento horizontal de Belém.

A ocupação urbana da Bacia do Mata Fome inicia com a construção dos conjuntos habitacionais produzidos pela $\mathrm{COHAB}$ através do governo federal e estadual e pelo Governo do Estado por meio do IPASEP, que tinham como principal objetivo alocar as populações oriundas das áreas de baixadas da área central de Belém. Os primeiros visavam atender famílias com rendimentos entre um e cinco salários mínimos e os segundos, os funcionários públicos estaduais (TRINDADE JUNIOR, 1998).

Os conjuntos habitacionais tiveram uma grande importância para o adensamento populacional no Mata Fome, pois foram os primeiros núcleos residenciais nesta área, provocando a ocupação desautorizada de terrenos desocupados em torno deles por pessoas sem condições financeiras para comprar ou alugar uma casa. "É na produção da favela, em terrenos invadidos, que os grupos sociais excluídos tornam- 
se, efetivamente, agentes modeladores, produzindo seu próprio espaço" (CORRÊA, 1995, p. 30). Estes grupos são uns dos agentes mais atuantes no Mata Fome, colocando a referida bacia numa posição de significativa relevância no cenário das ocupações desordenadas em Belém.

Como afirma Rodrigues (1996), o surgimento das "invasões" na área de expansão urbana de Belém está relacionado à construção dos conjuntos habitacionais, pois muitas vezes elas ocorrem contíguas aos conjuntos aproveitando a infraestrutura deles. É importante ressaltar que essas ocupações se reproduzem muito rapidamente no espaço urbano. Uma ocupação vai dando origem a outras, uma vez que alguns moradores após certo tempo de consolidação das ocupações vendem suas casas e ocupam novas áreas, fazendo surgir a "indústria das invasões" (FERNANDES, 1997).

A várzea do Mata Fome está tomada por essas ocupações, que se dão inicialmente por meio do desmatamento, da construção de palafitas e estivas de madeira. A partir da reivindicação dos moradores por infraestrutura urbana junto à prefeitura ocorre a segunda fase, que são os aterramentos, que se dão primeiramente com lixo ou outros detritos como caroço de açaí e serragem, depois vem o aterro definitivo que é feito com laterita ou piçarra. Desta forma, a várzea em ambiente urbano, é área desmatada, ocupada e aterrada (FERREIRA, 1995).

Com a construção do conjunto habitacional Cordeiro de Farias no Tapanã, dezenas de famílias passaram a ocupar as áreas no entorno do referido conjunto. Conforme destacou o jornal O Liberal em 20 de janeiro de 1989 apud (TRINDADE JUNIOR 1998, p.190) “o conjunto encontrava-se rodeado de invasões. Nos dois lados do conjunto existiam invasões".

A tendência dessas ocupações é o seu rápido espraiamento no espaço, uma vez que a população ocupa novos terrenos desocupados nas proximidades das primeiras ocupações. Por exemplo, as ocupações nos arredores do conjunto Cordeiro de Farias iniciaram com a ocupação de um terreno do IPASEP e depois os novos espaços sem nenhuma função social nos arredores do referido conjunto foram sendo ocupados (TRINDADE JUNIOR, 1998).

Outro agente atuante na Bacia do Mata Fome são os promotores imobiliários privados. Estes passaram a atuar no Mata Fome somente a partir da década de 1990 através da construção de condomínios fechados voltados para uma população de renda solvável. Esse processo, na verdade, tem ocorrido em toda a extensão da rodovia Augusto Montenegro e a partir da ocupação de novas áreas no espaço urbano, chegou aos limites da referida bacia. Van Dijk e Figueiredo (1997), na década de 1990, já chamavam atenção para a implantação de condomínios voltados para as classes de alta renda na rodovia Augusto Montenegro.

Assim, as grandes empresas imobiliárias com o objetivo de atender a uma parcela da população de maior poder aquisitivo, vem construindo alguns condomínios fechados na Bacia do Mata Fome. Este novo tipo de moradia ainda é muito incipiente na área objeto de estudo deste trabalho e seguindo à lógica da divisão social do espaço são produzidos nas áreas mais valorizadas do espaço urbano, 


\section{OS DESAFIOS DA GEOGRAFIA FÍSICA NA FRONTEIRA DO CONHECIMENTO \\ Instituto de Geociências - Unicamp \\ Campinas - SP \\ 28 de Junho à 02 de Julho de 2017}

localizando-se assim, ao longo das principais rodovias: Augusto Montenegro e Arthur Bernardes. Ao longo destas duas importantes vias de locomoção - ambas ligam Belém ao distrito de Icoaraci especialmente ao longo da primeira, vem surgindo alguns condomínios, como por exemplo, o Greenville Exclusive, o Cidade Jardim I e II, o Alto de Pinheiros, o Jardim Espanha, condomínios de médio padrão. Assim, vê-se cada vez mais, no Mata Fome, de um lado uma maior presença dos condomínios fechados e conjuntos habitacionais e de outro as ocupações espontâneas.

\section{Conflitos socioambientais resultantes dos usos da terra e da água}

Um dos resultados da ocupação urbana na Bacia do Igarapé Mata Fome foi a diversificação dos usos da terra, uma vez que houve a substituição de antigas formas espaciais como plantações, vegetação, fazendas, entre outras, por novas formas tais como casas, avenidas, comércio, etc.

Com base em trabalhos de campo e na interpretação de imagens do satélite Ikonos, do ano de 2006, o uso da terra foi classificado em seis classes: edificações, corpos hídricos, solo exposto, vias pavimentadas, vias sem pavimentação e cobertura vegetal (Tabela 1).

Tabela 1 - Uso da terra na Bacia do Mata Fome

\begin{tabular}{lll}
\hline Categorias & Área $\mathbf{K m}^{\mathbf{2}}$ & Área \% \\
\hline Edificações & 4,8 & $58,3 \%$ \\
Corpos hídricos & 0,02 & $0,3 \%$ \\
Solo exposto & 0,5 & $6,4 \%$ \\
Ruas pavimentadas & 0,2 & $2,9 \%$ \\
Vias sem pavimentação & 0,4 & $4,2 \%$ \\
Cobertura Vegetal & 2,4 & $27,9 \%$ \\
Total & 8,3 & $100 \%$ \\
\hline
\end{tabular}

Fonte: Elaborado e organizado pelos autores.

As edificações, que correspondem a 58,3\% do uso da terra, são todas as construções erguidas acima do solo como casas, fábricas, hospitais, etc. Dividimos esta classe em sete subclasses: área comercial, unidades industriais, ocupações espontâneas, conjuntos habitacionais, áreas institucionais, condomínios de status e espaços livres. A participação destas subclasses no contexto das edificações é a seguinte: ocupações espontâneas ou invasões (49,9\%), unidades industriais (25,6\%), as áreas institucionais ou terrenos pertencentes ao poder público $(10,1 \%)$, os conjuntos habitacionais $(6,1 \%)$, os condomínios de status $(4,1 \%)$, áreas comerciais $(2,2 \%)$ e espaços livres ou áreas de lazer $(2 \%)$. 
As ruas pavimentadas, que são as ruas asfaltadas, correspondem a 2,9\% do uso da terra no Mata Fome, indicando um baixo percentual de vias com calçamento na referida bacia. Já as vias não pavimentadas, ou seja, sem asfaltamento, correspondem a 4,2\% do uso da terra.

De acordo com Pivettaet. al. (2005) correspondem à cobertura vegetal todas as manchas de vegetação presentes no espaço urbano. Esta classe representa $27,9 \%$ do uso da terra na área de estudo. Segundo Luz e Rodrigues (2012), o parâmetro usado por diversos autores que estudam o Índice de Cobertura Vegetal (ICV) é que cidades, distritos e bairros devem apresentar $30 \%$ de cobertura vegetal para o equilíbrio da temperatura. Áreas com ICV inferior a 5\% têm-se a formação de desertos florísticos, onde há ausência de áreas verdes e grande desconforto térmico. Nesse sentido, a Bacia do Mata Fome está abaixo dos 30\% necessário para o equilíbrio da temperatura, porém está distante de ser considerada um deserto florístico.

Segundo Pivettaet. al. (2005), a categoria solo exposto diz respeito àquelas áreas não edificadas ou pavimentadas sem cobertura vegetal. No Mata Fome, essa classe é representada pelas áreas de quintais sem cobertura vegetal, campos de futebol e áreas pertencentes às indústrias erepresenta $6,4 \% \%$ do uso da terra, o que indica a existência de várias áreas desprovidas de qualquer cobertura vegetal, uma vez que, ela ocupa a terceira posição no uso da terra, o que é preocupante, pois ele implica a destruição da vegetação, importante indicador de qualidade ambiental. Além disso, a ocorrência de solo exposto favorece os processos erosivos.

A classe corpo hídrico no Mata Fome se refere ao igarapé de mesmo nome e é responsável por apenas $0,3 \%$ do uso da terra, a menor entre todas as classes. Apesar disso, mesmo estando altamente poluído, o igarapé possui grande importância para a vida da população, principalmente àquela parcela que reside próximo à desembocadura da bacia, que utiliza canoas para pescar. A figura 2 mostra o mapa de uso da terra no Mata Fome. 


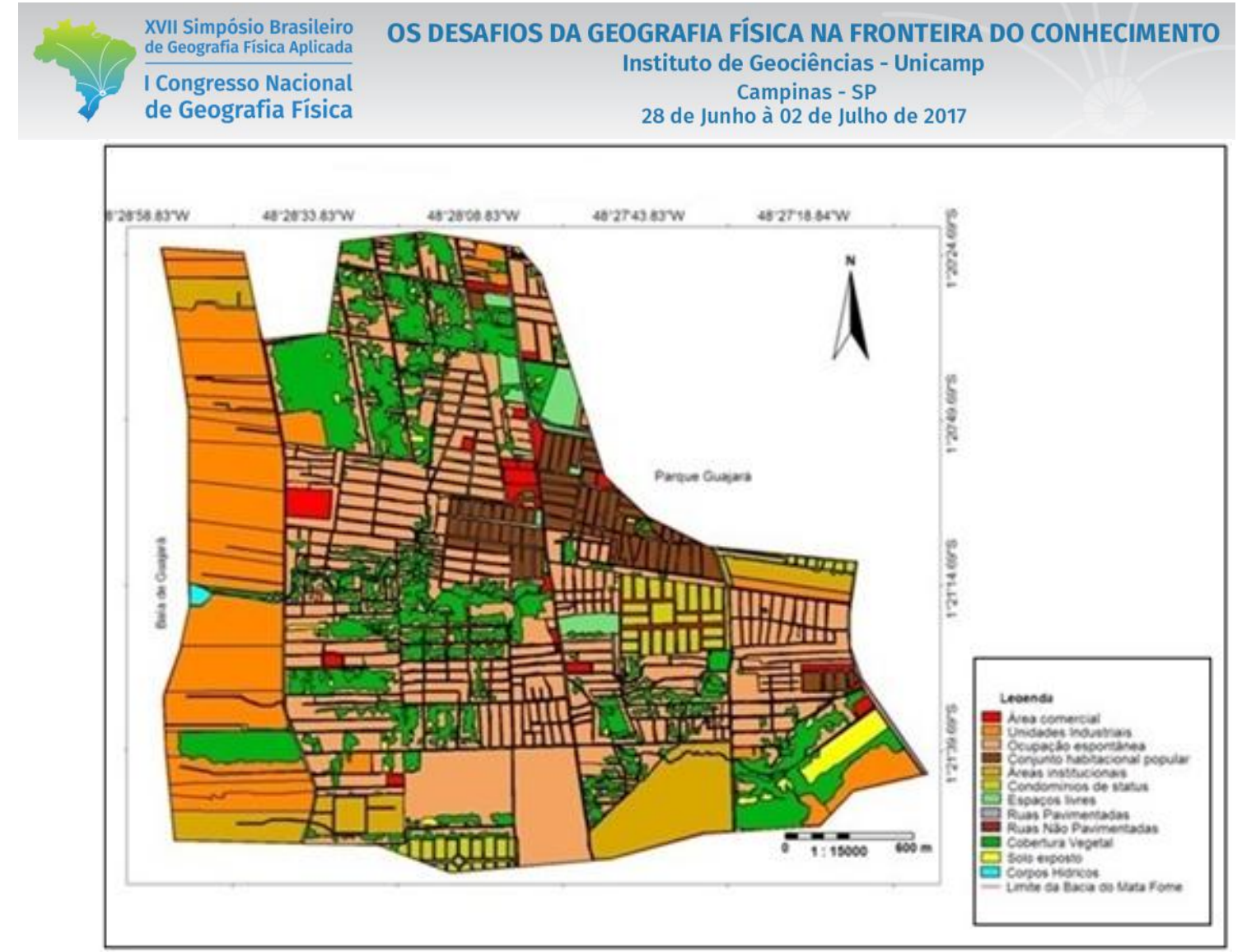

Figura 2 - Mapa de uso da terra da Bacia do Mata Fome. Elaborado por SILVA, 2013.

A Bacia do Mata Fome apresenta uma complexidade de usos e ocupação da terra e da água devido à presença de diferentes atores sociais na mesma, como os moradores dos conjuntos habitacionais, dos condomínios de status e das ocupações espontâneas. Os diferentes usos da terra e da água resultaram em conflitos socioambientais na referida bacia.

Segundo Little (2001), os conflitos socioambientais ocorrem pelo controle dos recursos naturais, derivados dos impactos ambientais e sociais decorrentes de determinados usos. Os conflitos também podem ocorrer por meio de reivindicação pelo acesso a serviços públicos. Acselrad (2004) afirma que os conflitos socioambientais ocorrem quando são envolvidos grupos sociais com modos diferenciados de apropriação, uso e significado do território. Ainda de acordo com Acselrad (2004), tais conflitos são originados quando pelo menos um dos grupos sofre ameaças quanto à continuidade das formas sociais de apropriação do seu meio. Estas ameaças podem acontecer por impactos indesejáveis ocorridos com o solo, água, ar ou sistemas vivos, decorrentes do exercício e das práticas de outros grupos.

Os atores sociais envolvidos nos conflitos na Bacia do Mata Fome são: os moradores das ocupações espontâneas, os proprietários fundiários e a Prefeitura Municipal de Belém. Os conflitos ocorrem em duas frentes: entre os proprietários fundiários e os moradores das ocupações espontâneas e entre estes últimos e o poder público, no caso a Prefeitura de Belém. 
Como dito anteriormente, para a análise dos conflitos socioambientais pelo uso da terra e da água na Bacia do Mata Fome foi utilizada a metodologia proposta por Thual (1996) e adaptada por Vianna (2002), que propõe a análise dos seguintes elementos como pares dialéticos: espaço, intenções e tempo. Onde o espaço é o local onde as relações de conflitos entre os atores sociais se desenvolvem. As intenções ou ações são os interesses de cada um dos grupos envolvidos no conflito em relação aos recursos e o tempo é o período de ocorrência do conflito.

No que se refere a esse trabalho, o espaço diz respeito à Bacia do Igarapé Mata Fome, em Belém. Já no que tange às intenções, é necessário especificar os interesses dos agentes sociais envolvidos no conflito. Os interesses dos moradores das ocupações espontâneas se referem à posse de terra enquanto territórios de moradias. Embora muitas das pessoas envolvidas em ocupações de terrenos, visem apenas obter ganhos financeiros com a posterior venda desses novos terrenos (TRINDADE JUNIOR, 1998), muitas delas não têm condições financeiras de adquirir um imóvel legalmente e a ocupação ilegal é a maneira de terem acesso à moradia. Quanto aos proprietários de terra, seus interesses estão voltados para a especulação imobiliária, pois como afirma Trindade Junior (1998), estes mantêm grandes extensões de terras nos espaços urbanos como reserva de valor, a fim de, no futuro, obterem grandes vantagens financeiras. No que se refere às ações da Prefeitura Municipal de Belém na Bacia do Mata Fome se limita aos poucos serviços públicos como coleta de lixo, iluminação elétrica, entre outros serviços que, de forma precária, oferece a uma parte da população.

Os conflitos entre os moradores das ocupações espontâneas e os proprietários fundiários se dão em decorrência da luta pelo acesso à terra como territórios de moradia e de vivência no caso dos moradores das ocupações ilegais e como reserva de valor por parte dos proprietários de terras. Little (2001) afirma que os conflitos socioambientais estão relacionados aos recursos naturais, aos espaços que contêm estes recursos, isto é, entre os agentes sociais que reivindicam essas terras como seu território de moradia e vivência. Acselrad (2004) mostra que os conflitos podem ocorrer quando um grupo sofre ameaças quanto à continuidade de acesso ou controle dos recursos como ocorre com os proprietários fundiários quando têm suas terras ocupadas e com os ocupantes quando há a reintegração de posse desses terrenos.

No Mata Fome, existem muitos terrenos desocupados, tendo como função a especulação imobiliária. As ocupações espontâneas são responsáveis por $49,9 \%$ das edificações do Mata Fome e elas se formam através da ocupação desses terrenos desocupados, constituindo o conflito com os proprietários dessas terras, uma vez que, ao terem suas terras ocupadas, os proprietários fundiários acionam a justiça para reaver a propriedade. A justiça, por sua vez, aciona as forças de segurança para realizar a reintegração de posse. Os ocupantes ilegais são retirados dessas terras, porém meses depois voltam a ocupá-las. Dentro desse contexto, para a consolidação das ocupações, entra a atuação do Estado que realiza a desapropriação dessas terras. Em alguns casos menos comuns, os próprios ocupantes, sob a 


\section{OS DESAFIOS DA GEOGRAFIA FÍSICA NA FRONTEIRA DO CONHECIMENTO \\ Instituto de Geociências - Unicamp Campinas - SP \\ 28 de Junho à 02 de Julho de 2017}

intermediação do Estado, através da Defensoria Pública realizam negociação direta com os proprietários da terra para não serem retirados do terreno como ocorreu na ocupação Visão de Deus no bairro da Pratinha. Essa ocupação teve inicio em 2010. A empresa Porto Rico, proprietária do terreno, conseguiu a reintegração de posse. Porém, meses depois a terra voltou a ser ocupada. Em maio de 2016, sob a intermediação da Defensoria Pública do Pará, entraram em acordo com a empresa proprietária para permanecerem no local através do pagamento, por parte de cada morador, de pequenas parcelas mensais (Figura 3).

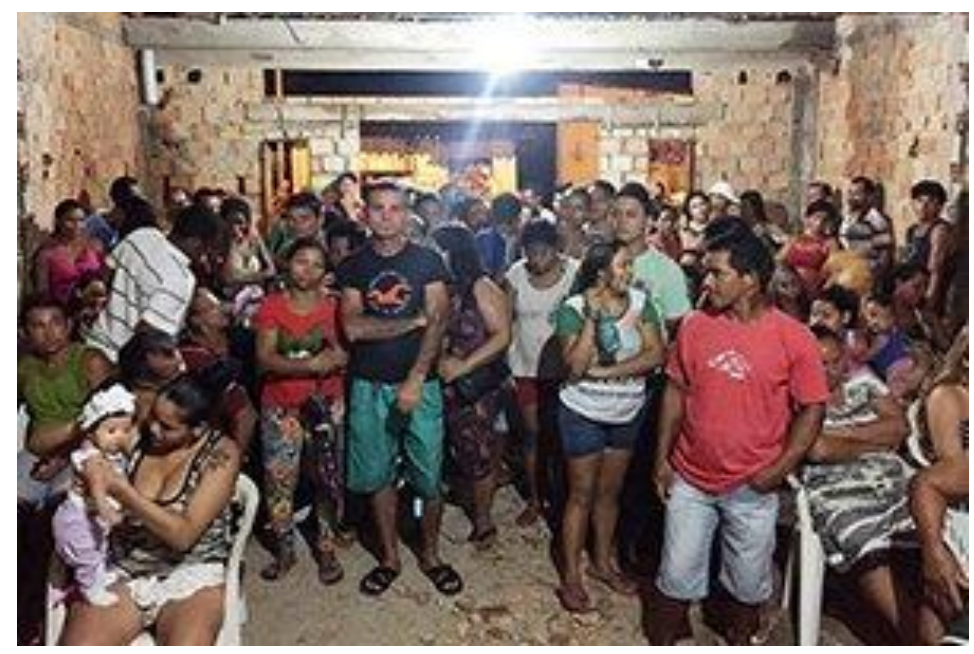

Figura 3 - Reunião de conciliação entre moradores da ocupação Visão de Deus e a empresa Porto Rico. Fonte: ANADEP, 2016.

Vale ressaltar que nem todas as ocupações "vingam" (termo usado pelos ocupantes para se referi à consolidação da ocupação), uma vez que, em alguns desses terrenos, os ocupantes permanecem neles por dois, três anos, constroem e vão substituindo as moradias improvisadas de lonas e madeiras velhas, por casas de madeira e até mesmo de alvenaria. Após esse período, o dono do terreno consegue a reintegração de posse e essa população é retirada e suas moradias destruídas.

Quanto ao tempo de duração dos conflitos entre os moradores das ocupações espontâneas e os proprietários de terra é variável. De acordo comCedir da Costa Ribeiro, presidente da Comunidade Bom Jesus II, estes conflitos duram em média quatro anos. Porém ele ressalta que existe ocupação no Mata Fome com quase 20 anos, cujos moradores ainda estão em conflitos com o dono da terra.

Quando os ocupantes conseguem permanecer nas terras ocupadas, surge então um novo conflito, desta vez com a Prefeitura de Belém. A origem deste conflito diz respeito à luta pelo serviço de abastecimento de água potável, pois como afirmam Little (2001) e Acselrad (2004), os conflitos socioambientais podem ocorrer pelo uso dos recursos naturais. Ou seja, o conflito é pelo uso da água.

$\mathrm{Na}$ Bacia do Igarapé, apenas os conjuntos habitacionais, os condomínios de status e algumas ocupações espontâneas mais antigas têm acesso a serviços de abastecimento de água. A grande maioria da população usa água de poços de baixa profundidade. Isso tem levado a diversos protestos 


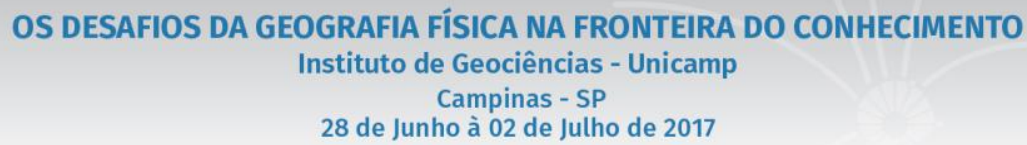

com a finalidade de chamar a atenção do poder público para a falta de saneamento básico na área, do qual o abastecimento de água potável faz parte. Assim, os moradores de várias ocupações espontâneasinterditam as principais vias como as rodovias Arthur Bernardes e do Tapanã a fimde sensibilizar a prefeitura para este problema que tanto afeta a vida dessas populações. Outras vias menores também às vezes são fechadas como forma de protestos (Figura4).

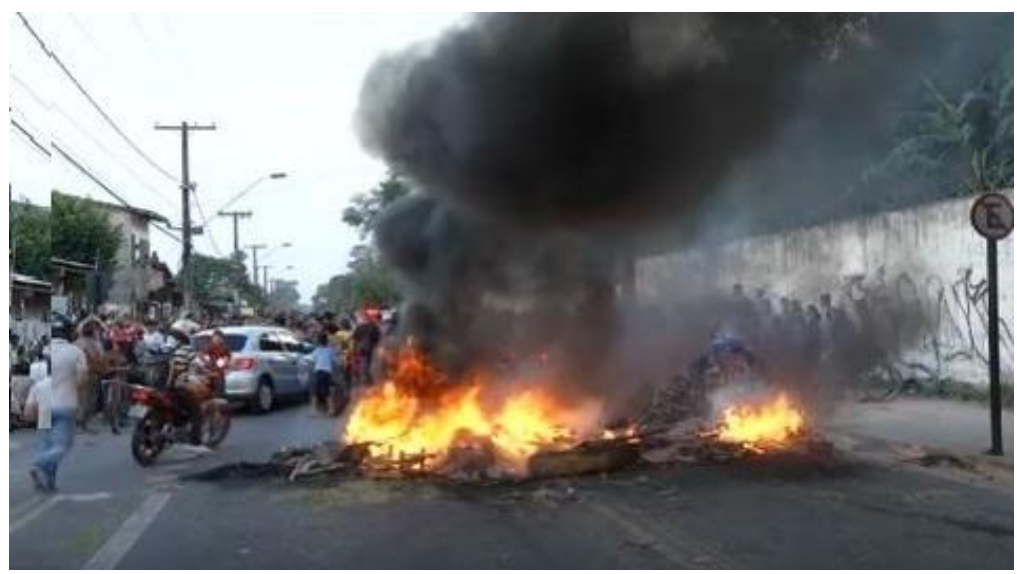

Figura 4 - Protesto por abastecimento de água no bairro Pratinha. Fonte: Jornal Diário do Pará, 2012.

Engana-se quem pensa que são apenas as ocupações recentes que reivindicam serviços de abastecimento de água potável. Existem ocupações bastante antigas como a conhecida como Residencial Novo Milênio, localizado na Rua John Engelhard na Pratinha, que há quase 20 anos, luta pelo acesso a esse serviço.

Sobre a falta abastecimento de água potável na Bacia do Mata Fome, o depoimento abaixo é interessante:

Moro aqui nesta comunidade há quase 20 anos. Fui um dos primeiros moradores. Naquela época era normal não ter água encanada, pois a invasão era nova, mas hoje em dia é até um absurdo. Pagar para escavar poço sai muito caro. O metro do poço é 18 reais. Além disso, o fato de usarmos bombas para jogar a água para a caixa d'água encarece o valor da energia elétrica. (Breno Moreira, 42, morador do Residencial Novo Milênio).

Na Comunidade Bom Jesus II, localizada às margens do Igarapé Mata Fome no bairro da Pratinha, apenas $0,92 \%$ das moradias eram abastecidas pelo abastecimento de água da rede geral e a grande maioria por água de poços de pequena profundidade (SILVA, 2013). Esta ocupação não é recente, tendo mais de 15 anos de existência.

Quanto ao tempo de conflito entre os moradores das ocupações espontâneas e a Prefeitura de Belém pelo acesso aos serviços de abastecimento de água é também variável, uma vez que em algumas comunidades, a prefeitura atende às reivindicações e o conflito especificamente por serviço de água cessa. Entretanto, há conflitos que tem quase duas décadas como o caso do Residencial Novo Milênio, 
onde todo ano, segundo o morador Breno Moreira, a população interdita ruas como protesto pela ausência deste serviço. Assim, o conflito permanece. De acordo com Cedir Ribeiro, presidente de comunidade na referida bacia, a justificativa da prefeitura para não oferecer o serviço de abastecimento de água é que essas áreas não são legalizadas. Apesar disso, segundo Ribeiro, todo ano o talão do Imposto Predial e Territorial Urbano (IPTU), chega às residências dos moradores.

\section{Conclusão}

Assim, vê-se que a ocupação urbana na Bacia do Igarapé Mata Fome, resultou em diferentes usos e ocupação da terra e da água, dos quais um desses usos são as ocupações espontâneas, habitadas por pessoas com parcos recursos financeiros. Conclui-se, que a disputa por terrenos para de moradia, ocasionou conflitos socioambientais na referida bacia. Nesse sentido, vê-se que esses conflitos têm como causa o acesso à terra como território de moradias por parte dos moradores das ocupações ilegais e o direito de permanecer com a propriedade da terra por parte dos proprietários fundiários, que não querem perder suas terras, que têm como função a especulação imobiliária. Na outra frente do conflito, estão os moradores das ocupações espontâneas e a Prefeitura Municipal de Belém e sua causa é a falta de serviços de abastecimento de água potável às populações das ocupações ilegais.

Desse modo, o acesso à terra, enquanto territórios de moradias e as reivindicações pelo acesso ao abastecimento de água, temresultado em conflitosna Bacia do Mata Fome, levando à interdição de vias públicas por parte dos moradores como forma de pressionar o poder público a lhes oferecer o que reivindicam. Tais conflitos são frutos do déficit habitacional na sociedade brasileira, onde muitos cidadãos de baixo poder aquisitivo, têm como única forma de acesso à moradia, ainda que precárias, as ocupações ilegais de terrenos públicos ou privados e também devido à falta de atuação do poder público que não tem dotado tais espaços, mesmo aqueles com quase 20 anos, de serviços básicos como o serviço de abastecimento de água potável tão reivindicado pelos moradores das ocupações espontâneas da Bacia do Igarapé Mata Fome.

\section{Referências}

ACSELRAD, H. As práticas espaciais e o campo dos conflitos ambientais. In: ACSELRAD, H. (Org.) Conflitos Ambientais no Brasil. Rio de Janeiro: Fundação Heinrich Böll, 2004.

ANADEP. Defensoria Pública do Pará beneficia mais de 220 famílias em ocupação. Disponível em: $<\mathrm{http} /$ /www.anadep.org.br/wtk/pagina/materia?id=27519>. Acesso em jan. 2017.

CORRÊA, R. L. O espaço urbano. (Série Princípios). 3. ed.São Paulo: Ática, 1995.

DIÁRIO DO PARÁ. Pratinha II sofre com falta de saneamento. Disponível em:

<http://www.diarioonline.com.br/noticias/para/noticia-374364-pratinha-ii-sofre-com-falta-de-saneamento.html>. Acesso em: 20 de dez. 2016. 
FERNANDES, R. P. Produção, apropriação e consumo do espaço urbano habitacional na cidade de Belém. 1997. 214 f.: Dissertação (Mestrado em Arquitetura e Urbanismo) - Faculdade de Arquitetura e Urbanismo, Universidade de São Paulo, 1997.

FERREIRA, C. F. Produção do espaço urbano e degradação ambiental: um estudo sobre a várzea do igarapé do Tucunduba (Belém-PA). 1995. 160 f. Dissertação (Mestrado em Geografia Física) - Faculdade de Filosofia, Letras e Ciências Humanas, Universidade de São Paulo, 1995.

LITTLE, P. Os Conflitos Socioambientais: um Campo de Estudo e de Ação Política. In: BURSZTYN, M. (Org.). A Difícil Sustentabilidade: Políticaenergética e conflitos ambientais. Rio de Janeiro, Brasil: Editora GaramondLtda, 2001.

LUZ, L. M.; RODRIGUES, J. E. C. Atlas de áreas verdes da cidade de Belém. GAPTA/UFPA, Belém, 2012.

PIVETTA, A. et. al. Sistema de classificação da cobertura do solo para fins de composição entre cidades e bairros. In: Simpósio brasileiro de Geografia Física Aplicada. USP. 2005.

RODRIGUES, E. Aventura urbana: urbanização, trabalho e meio-ambiente em Belém. Belém: UFPA. NAEA, 1996. $281 \mathrm{p}$.

SILVA, M. J. D. Uso do solo e indicadores de qualidade de vida na Bacia do Mata Fome em Belém-PA: o estudo de caso das ocupações espontâneas, conjuntos habitacionais e condomínios de status. Trabalho de Conclusão de Curso (Graduação em Geografia) - Faculdade de Cartografia e Geografia, Universidade Federal do Pará, 2013. 77 p.

TRINDADE JUNIOR, S. C. A Cidade dispersa: os novos espaços de assentamentos em Belém e a reestruturação metropolitana. 1998. 395 f.: Tese (Doutorado em Geografia Humana) - Faculdade de Filosofia, Letras e Ciências Humanas, Universidade de São Paulo, São Paulo, 1998.

VAN DIJK, A. I. N.; FIGUEIREDO, L. A. A Ação do capital imobiliário na produção de habitação popular: estudo na área de expansão de Belém. 1997. 87 f. Monografia (especialização em política científica e tecnológica para a Amazônia) - Núcleo de Altos Estudos Amazônicos, Universidade Federal do Pará, Belém, 1997.

VIANNA, P. C. G. O Sistema aqüífero Guarani (SAG) no Mercosul. Tese de Doutorado em Geografia. São Paulo: Universidade de São Paulo, 2002. 113p. 